\title{
APPLICATION OF HUMAN EXCRETA ON THE FARMS AS AN EFFECTIVE OPTION TO THE UPTAKE AND REPLICATION OF ECOLOGICAL SANITATION (ECOSAN) IN BURERA DISTRICT, RWANDA
}

\author{
Celestin Banamwana ${ }^{1}$ David Musoke ${ }^{2}$, Nazarius Mbona Tumwesigye ${ }^{2}$ Theoneste \\ Ntakirutimana ${ }^{1}$ Pierre Dukuziyaturemye ${ }^{1}$ \\ ${ }^{1}$ College of Medicine and Health Sciences, University of Rwanda Po Box 3286 Kigali Rwanda \\ ${ }^{2}$ School of Public Health, College of Health Sciences, Makerere University, Po Box 7062 Kampala Uganda
}

Celestin Banamwana ${ }^{1}$ Corresponding Author

cbanamwana@nursph.org +250785160088

Keywords: Ecological sanitation (Ecosan) technology, adoption, human excreta, productive sanitation, fertilizer, farmers.

\begin{abstract}
The ecological sanitation (Ecosan) technology continues to be challenged by diverse factors including exposure of human excreta to the users in different geographical settings. The purpose of the study is to understand the linkage between the uptake of Ecosan technology and the application of human excreta on the farms among farmers in Burera district. A quantitative study was conducted to assess the linkage between the application of human excreta on the farms and the uptake of Ecosan technology among farmers of Burera District, Northern Province of Rwanda. By using a multistage sampling strategy, a sample of 361 household farmers was selected in the sectors of Rugarama, Gahunga and Cyanika in the District of Burera where the Ecosan technology has been mostly implemented at the household level.
\end{abstract}


Findings show that Ecological sanitation technology is favorable among females and $70 \%$ of females prefer to use it as sanitation facilities due to its privacy and design compared to the pit latrine technology. In addition, the application of human excreta on the farm was high and $60 \%$ of farmers apply excreta on the farmers especially when there is a time of emptying excreta from their sanitation technologies. However, only $3 \%$ of the users of Ecosan technology apply also human excreta as Ecosan products on their farms.

This implies that there is a need to scale up the Ecosan technology in the community of Burera district to optimize the proper use of human excreta. The high uptake of Ecosan technology will evolve the implementation strategies such as community education, the supply of Ecosan materials in the community and the construction of Ecosan technology. This will boost sanitation coverage and increase crop production in Burera district by taking into account the community health as well as the environmental aspect

\section{INTRODUCTION}

The uptake of Ecological sanitation (Ecosan) technology in the community of farmers can increase productivity and farmers' livelihood (Guzha, Nhapi, \& Rockstrom, 2005). Nevertheless, the management of soil fertility and sanitation could be achieved by promoting readily available nutrients from Ecosan products (Waithaka, Thornton, Shepherd, \& Ndiwa, 2007). The Ecosan technology known as Urine Diversion Dry Toilets (UDDTs) has been a response to sanitation and agriculture problems. Such toilets are known to separate both urine and feces and allow onsite treatment for reuse as fertilizers on farms (Mukasine, 2014). However, the uptake and spread of Ecosan toilets are critical and slow in the East African region. Although people are willing to 
reduce water usage and to apply excreta in farms for increasing crop yields, the use of such excreta manure among farmers is not a common practice (Lamichhane \& Babcock, 2013).

The uptake of Ecosan technology requires a level of change in people's mindset through the interventional program. Then, a shift from fear of feces of being contaminated to the safe use of Ecosan fecal product among communities was engaged through different interventions on change behavior in Nepal and China (Calvert et al. 2004). Ecosan technology has been adopted for thousands of years in Asia, particular in China and the practice of using urine for agriculture has been initiated in Japan about 900 years ago (Mayo \& Mubarak, 2015). For example, the application of human excreta has become an agriculture tradition for centuries in Vietnam and Northern part of China (Nhan et al., 2008). The introduction of Ecosan in Europe was not well accepted and was considered as stranger technology from Asiatic countries (Mayo \& Mubarak, 2015).

Such misconception of Ecosan has changed since UN Earth Summit 1992 held in Rio de Janeiro focusing on environmental pollution (Muellegger, 2005). The Ecosan was found to provide cobenefits either by improving resource efficiency, improve access to clean water and basic sanitation or promote food security(Haq \& Cambridge, 2012a). The country such as Sweden has changed the local culture of flushing and discharges the excreta at their homes. It has initiated the installation of urine diversion collection tanks on local farmers who sprayed it on their crops (Jewitt, 2011). 
The uptake of Ecosan technology as an option in agriculture raise up the standard of living of poor people by breaking down socio-culture taboos (Uddin, Muhandiki, Sakai, Al Mamun, \& Hridi, 2014). While a number of studies have stressed the risks of touching human excreta in Muslim communities whereby the taboos of touching urine and feces before praying is a great sin in Bangladesh Muslims, the evidence is sparse in the community of Burera district regarding the application of human excreta and willingness to use the Ecosan for onsite treatment. However, other studies indicate that people could shift from cultural barriers to the adoption of Ecosan due to the income from agriculture and sanitation (Hulland, Martin, Dreibelbis, J, \& Winch, 2016)

Ecosan technology has been established to close the loop between sanitation and agriculture (Haq \& Cambridge, 2012b). However, technology adoption has been challenged in different geographic settings by socio-cultural, economic and demographic factors (Waithaka et al., 2007). Both spatial and cultural boundaries are the main challenges that hamper the geographic distribution of Ecosan technology (Pearson \& Mcphedran, 2008). The research done in Malawi, Lilongwe and Blantyre cities on sanitation technology choice, indicate that Ecosan technology's adoption is still critical (Chunga, Ensink, Jenkins, \& Brown, 2016). Hence, the technology is also on an immature stage in both cities despite the made differences from other existing sanitary facilities by providing fertilizer and land conservation (Richard, 2015).

The application of Ecosan products on farms is not popular (Seleman \& Bhat, 2016). Despite, the willingness of people to reduce water usage and application of manure in farms for increasing crop yields, the use of human excreta manure treated through Ecosan technology called "Ecosan products" is not a common practice (Lamichhane \& Babcock, 2013). Rwandan sanitation facility 
coverage was $73,1 \%$ of households in rural areas as indicated by the National survey (EICV5)(2012/2017). Since 2006, in partnership with UNICEF and the Ministry of Infrastructure (MININFRA) started to implement Ecosan technology to boost sanitation coverage and to promote productive sanitation in volcanic regions (MININFRA, 2012). In the beginning, delivered 1000 Ecosan technology slabs were constructed for poor households in Burera district and later SNV continued to spread technology in the region (Ekane, Nykvist, Kjellén, Noel, \& Weitz, 2014). However, the report made by SNV in 2014 showed a very big gap in achieving sustainable use of Ecosan technology in Burera district. Before, the introduction of Ecosan technology in 2007 in the district, the human excreta was waste, ever used in farming and was also locally termed "amazirantoki" meaning " touching is forbidden"(Ekane et al., 2014). The dos and don'ts approach by foreign NGOs such as UNICEF and SNV during Ecosan implementation were only used in schools and at households. Consequently, many Ecosan technology slabs found used in the construction of pit latrines and about 20 blocks of toilets built in public places in Burera district were abandoned for lacking composting site. In addition to that, 16 blocks of Ecosan technology built-in public schools were not operating due to a lack of proper management (MININFRA, 2012). From the time, it was noted that only $20 \%$ of farmers use excreta manure in their farms in Burera district. Unfortunately, the use of protective equipment from emptying to applying excreta to the farm is not common practice (Ekane, Mertz, Slovic, Kjellén, \& Westlund, 2016).

Even though Ecosan technology comes with a clear advantage of a new approach to productive sanitation, it is grounded by theory on human excreta disgust (Robinson, 2005). Therefore, its uptake in new setting requires effective implementation strategies for behavior change (Dickin, Dagerskog, Jiménez, Andersson, \& Savadogo, 2018). It is in this perspective, a study aimed to 
understand the linkage between the uptake and the application of human excreta on the farms was conducted in Burera district, Rwanda.

\section{METHODS AND MATERIALS}

\subsection{The scope of the study area}

The study was conducted in Burera district in three sectors of Rugarama, Cyanika, and Gahunga where mostly implemented Ecosan technology. The district of Burera is located in the volcanic region which makes it have rocky soil, difficult to dig and therefore, Ecosan latrines are suitable for the area and Ecosan technologies particularly Urine Diversion Dry Toilets are common in the above sectors.

\subsection{Study design and sampling strategy}

A cross-sectional study that uses quantitative methods was carried out in the community of Burera district targeting farmers at household level. The sample size of households in three sectors was calculated based on the formula of Kish Leslie (1955). Due to unavailable of prevalence on utilization of Ecosan in Rwanda and similar geographical setting, we assumed true population prevalence on the utilization of Ecosan technology estimated to $50 \%$ at $95 \%$ confidence interval with an absolute error of 5\%. The calculated sample size was 384 household farmers and the real number of participants was 361 participants. 1-P = the probability of not utilizing of Ecosan technology. $\mathrm{Z} \alpha=$ Standard normal deviate at $95 \%$ confidence interval corresponding to $1.96 . \delta=$ Absolute error between the estimated and true population prevalence of 5\%. By multistage stratified sampling, data was collected at the village level of Rugarama, Cyanika and Gahunga sectors. In addition, the household members were randomly selected to participate in the study. 


\subsection{Data collection method}

Data was collected by a research-administered questionnaire translated in Kinyarwanda. The respondents provided responses on the demographic characteristics; knowledge and practices on excreta management and the utilization of Ecosan technology and products. The research participants agreed to participate in research and therefore, signed the consent form with research assistants.

\subsection{Data management and analysis}

The data was entered into Epidata 2002 computer software package, cleaned, exported, and analyzed in MS excel. A descriptive statistical analysis on uptake and spread of Ecosan technology versus the application of human excreta was done. Therefore, the tables were presented showing the percentages of responses.

\subsection{Ethical considerations}

A written permission from the district of Burera to conduct a study was delivered to Principal Investigator after submitting an ethical clearance given by the University of Rwanda/College of Medicine and Health Sciences/Institution of Review Board (IRB). Participation in the study was voluntary and participants provided written informed consent after explanation of research assistants about the proposed research including the anticipated risks and potential benefits before taking part.

\section{RESULTS}

The data was collected in 361 household farmers in the community where Ecosan technology has been implemented at home. The sample was collected based on the size of 8007 population of 
Rugarama, 5635 population of Gahunga, and 5094 population of Cyanika with 154 Participants, 107 participants, and 100 participants respectively.

Table 3. 1: Gender preference of Ecosan technology in Burera district $(\mathrm{N}=361)$

Options Gender Total

$\begin{array}{ll}\text { Male (Number } & \text { Female (Number } \\ \text { and } \%) & \text { and } \%)\end{array}$

Like of Ecosan Technology $147(66 \%) \quad 97(70 \%) \quad 242(67 \%)$

Dislike of Ecosan Technology $75(34 \%) \quad 42(30 \%) \quad 119(33 \%)$

Total $222(62 \%) \quad 139(38 \%) \quad 361(100 \%)$

The table (3.1) indicates that the majority of females at $70 \%$ prefer to use Ecosan technology at home, whereby $66 \%$ of males prefer Ecosan technology. The females are mostly involved in sanitation practices and the Ecosan technology is easier to clean than conventional latrines such as pit latrines.

Table 3. 2. The knowledge about the Ecosan technology among farmers $(N=361)$

\begin{tabular}{lcc}
\hline \multicolumn{1}{c}{ Options } & Respondents(N) & Percentage \% \\
\hline Excellent & 5 & $1 \%$ \\
\hline Very good & 45 & $12 \%$ \\
\hline Good & 221 & $61 \%$ \\
\hline poor & 90 & $26 \%$ \\
\hline
\end{tabular}

The table (3.2) indicates that about $61 \%$ of people in the community of Burera District are aware of the Ecosan technology and only 1\% well understands the Ecosan technology. 


\begin{tabular}{lcc}
\hline $\begin{array}{l}\text { The ways of receiving } \\
\text { Ecosan technology }\end{array}$ & Respondents(Number) & Percentage (\%) \\
\hline By hand from NGOs & 64 & $63 \%$ \\
\hline Supply of Ecosan materials & 32 & $31 \%$ \\
\hline Construction at self & 6 & $6 \%$ \\
\hline
\end{tabular}

Table 3.3. Information about owners of Ecosan technology $(N=102)$

The table (3.3) shows that most people at 64\% received the Ecosan technology from the NGOs While only $6 \%$ were constructed themselves the Ecosan technology. This indicates that farmers are not yet able to construct the Ecosan technology at home due to the diverse factors including the capital of construction

Table 3.4. Utilization of Ecosan technology as sanitation option in the community $(\mathrm{N}=102)$

\begin{tabular}{lcc} 
Level of utilization & Respondents (Number) & Percentage (\%) \\
\hline Very good & 12 & $12 \%$ \\
\hline Good & 30 & $29 \%$ \\
\hline Bad & 52 & $51 \%$ \\
\hline Not at all & 8 & $8 \%$ \\
\hline
\end{tabular}

The table (3.4) shows that $8 \%$ of those who have Ecosan technology are not utilized at all. The majority of $51 \%$ utilize badly technology. 
Table 3. 5. Utilization of Ecosan technology and human excreta in the community $(\mathrm{N}=361)$

\begin{tabular}{lcc}
$\begin{array}{l}\text { Use of Ecosan technology } \\
\text { and human Excreta }\end{array}$ & Respondent (Number) & Percentage (\%) \\
\hline $\begin{array}{l}\text { Ecosan technology as } \\
\text { sanitation only }\end{array}$ & 84 & $23 \%$ \\
\hline $\begin{array}{l}\text { Human excreta as } \\
\text { fertilizer }\end{array}$ & 216 & $60 \%$ \\
\hline $\begin{array}{l}\text { Ecosan technology and } \\
\text { human excreta as } \\
\text { fertilizer }\end{array}$ & 10 & $3 \%$ \\
\hline Not at all & 51 & $14 \%$ \\
\hline
\end{tabular}

The table (3.5) shows that most people utilize human excreta on their farms at $60 \%$ including people who have Ecosan technology and people who have other sanitation technology. However, only $3 \%$ of people utilize both the Ecosan technology and human excreta as fertilizer on the farms.

Table 3.6. Composting period of the fecal product treated through Ecosan technology $(\mathrm{N}=102)$

\begin{tabular}{lcc} 
Composting period & Number & Percentage (\%) \\
\hline Six months & 46 & $45 \%$ \\
\hline Between six and nine months & 6 & $6 \%$ \\
\hline More than six months & 14 & $14 \%$ \\
\hline Less than six months & 30 & $29 \%$ \\
\hline Don't know & 6 & $6 \%$ \\
\hline
\end{tabular}


This table (3.6) shows that many people tend to wait for compost excreta through Ecosan technology at least over a period of six months (45\%), and $29 \%$ of them are not waiting for at least six months for composting fecal products.

Table 3.7. Plants mostly applied to human excreta fertilizers $(\mathrm{N}=361)$

\begin{tabular}{lcc}
\hline Plants & Number & Percentage (\%) \\
\hline Irish potatoes & 68 & $19 \%$ \\
\hline Maize & 212 & $59 \%$ \\
\hline Beans & 40 & $11 \%$ \\
\hline Others & 41 & $11 \%$ \\
\hline
\end{tabular}

This table (3.7) shows that $59 \%$ of those who use excreta fertilizers mostly apply it on Maize and $11 \%$ only apply human excreta on beans.

\section{DISCUSSION}

The goal of this paper was to understand the linkage between the uptake and spread of Ecological sanitation (Ecosan) technology and the application of human excreta on the farms among farmers of Burera district, Rwanda. The findings showed that most females prefer to use Ecosan technology as sanitation facilities at home. These findings are complying with the review paper on sanitation preference done by Pearson and Mcphedran (2008) at the London School of Hygiene, whereby Ecosan was a favorable choice among females due to its privacy and design. The shortfalls of conventional sanitation technologies, which are common in Burera district notably, pit latrines make Ecosan technology to be popular in the community of Burera district. 


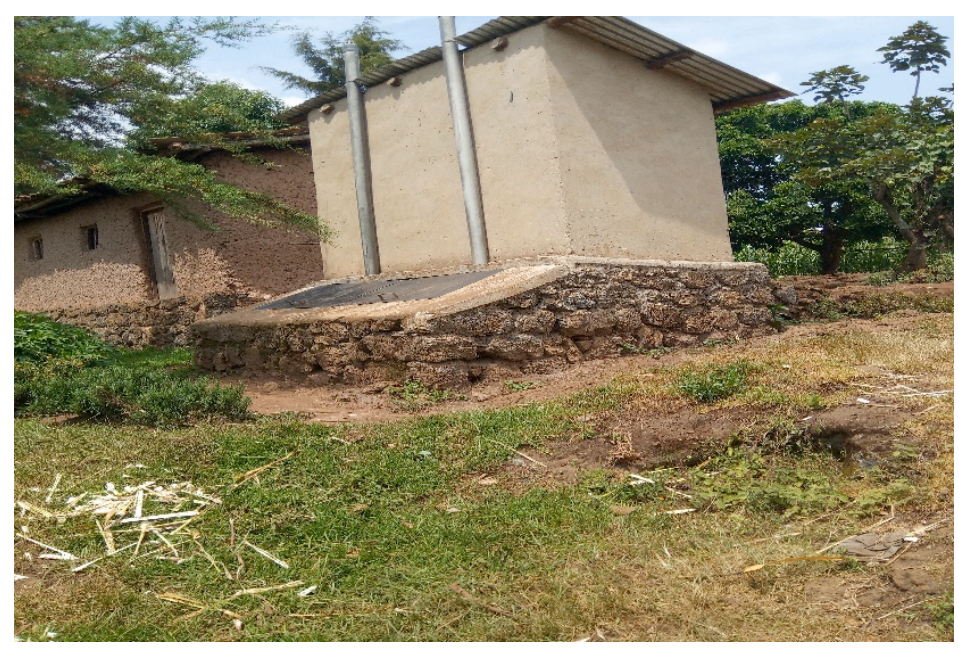

Figure 4. 1. The Ecosan technology/UDDT constructed by SNV at household in Rugarama Sector.

However, the level of knowledge on the efficient utilization of Ecosan technology is critical and most people know the technology from their neighbors. As a result, the majority received the technology by hand from NGOs such as UNICEF and SNV and only a few people construct the Ecosan for themselves. This implies the poor management of excreta through small pit latrines as the source of poor household sanitation from full fecal pit latrines. Moreover, the farmers fail to separate feces from urine through pit latrines and consequently, they are exposed to such mixed excreta during application on the farms, which are the source of parasitic infections. Although people have the Ecosan at home level, their operation and maintenance for productive sanitation are still sub-standard and the majority do not know the time of storage of fecal products which implies the application of unsafe excreta on their farms.

A study was done in the UK by Jewitt and Sarah (2011) on threat and opportunity presented by human wastes highlighted that farmers can be attracted by advantages from human excreta fertilizer and therefore, a need for appropriate technology to treat and safe such wastes. The study finding comprises with such a study because the farmers of Burera have willing to use the 
excreta products particularly the users of Ecosan technology. Therefore, the application of excreta for crop production to increase the uptake of Ecosan technology in farmers.

It is known that the district of Burera presents the rocky soil and hard to dig a latrine and also predominantly with agriculture. The most implemented pit latrines are between 2 to 3 meters deep and sometimes full of excreta. Apart from issues of sanitation at household level such as bad smell, presence of vectors such as flies, such pit latrines are not environmentally friendly when the full pit of excreta floods the excreta in the surrounding environment. In the framework of reducing flooding disasters especially in the rain season, many people tend to empty their fecal pit and apply excreta on the farms and others dump them in water bodies due to the lack of dumpsite. This is justified in (Table.3.3) where the majority of people apply for human excreta on the farms.

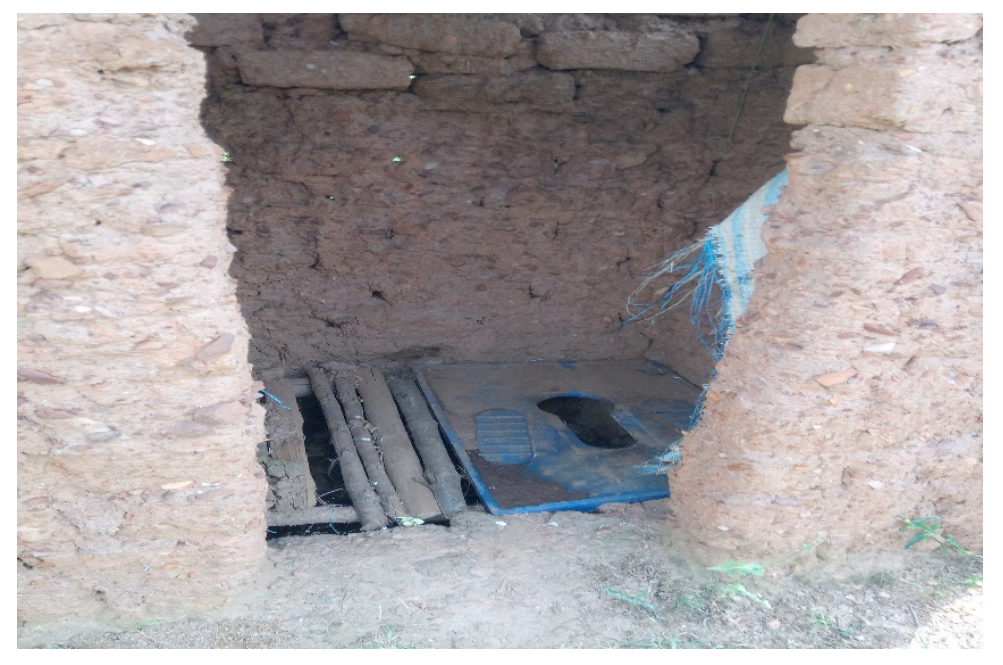

Figure 4. 2. The urine diversion pit latrines using Ecosan slabs received from UNICEF 2015 in Gahunga Sector.

However, such unseparated urine and feces contain a full of microorganisms and hence a higher prevalence of $62.7 \%$ parasitic infection in Burera district (USAID, 2015). The same concerns have raised up the high choice of Ecosan technology, which could be a holistic solution to treat, 
and to safer human excreta for further application on the farms. Yet, the study findings presented the efficient utilization of Ecosan technology with human excreta for sanitation and agriculture options is still critical in Burera district. The study is limited to the application of human excreta as a core factor to the uptake and replication of Ecosan technology in the community of Burera district, Rwanda. Further research is needed on the health risks and other factors that affect the uptake and replication of Ecosan Technology in the community of Burera district, Rwanda.

\section{CONCLUSION AND RECOMMENDATION}

A series of studies have provided evidence on the adoption of Ecological sanitation (Ecosan) technology in the community of farmers. Yet, there is an ambiguity on complex factors that hinder or driver of the uptake and replication of Ecosan technology in different geographical settings. The study revealed that there is a high linkage of the use of human excreta as fertilizer and uptake of Ecosan technology in Burera district, Rwanda. However, the slowdown of the uptake of Ecosan technology and its replication in the community is due to the lack of proper implementation strategy in the community that can build the trust of the technology on health and crop production aspects. Therefore, the findings of the study show that the uptake and replication of Ecosan technology are not affected by exposure of the human excreta to the people but other factors that can be investigated in further researches. There is a need to scale up the Ecosan technology to respond to the shortfalls in the sanitation and to increase crop productivity. Therefore, strategies such as community education and training, building Ecosan technology and supply of material and consumables in the community is urgently recommended. 


\section{Acknowledgments}

This research was supported by the Consortium for Advanced Research Training in Africa (CARTA). CARTA is jointly led by the African Population and Health Research Center and the University of the Witwatersrand and funded by the Carnegie Corporation of New York (Grant No--B 8606.R02), Sida (Grant No:54100113), the DELTAS Africa Initiative (Grant No: 107768/Z/15/Z) and Deutscher Akademischer Austauschdienst (DAAD). The DELTAS Africa Initiative is an independent funding scheme of the African Academy of Sciences (AAS)'s Alliance for Accelerating Excellence in Science in Africa (AESA) and supported by the New Partnership for Africa's Development Planning and Coordinating Agency (NEPAD Agency) with funding from the Welcome Trust (UK) and the UK government. The statements made and views expressed are solely the responsibility of the Fellow".

We acknowledge the knowledge and skills of scientific writing and communication gained before starting to write this paper from the University of Makerere.

We acknowledge the role played by the University of Rwanda, College of Medicine and Health Science for the provision of Ethical clearance as supporting documents to get the permission of collecting data. 


\section{REFERENCES}

Chunga, R. M., Ensink, J. H. J., Jenkins, M. W., \& Brown, J. (2016). Adopt or Adapt : Sanitation Technology Choices in Urbanizing Malawi, 11 . https://doi.org/10.1371/journal.pone.0161262

Dickin, S., Dagerskog, L., Jiménez, A., Andersson, K., \& Savadogo, K. (2018). Understanding sustained use of ecological sanitation in rural Burkina Faso. Science of the Total Environment, 613-614(November), 140-148. https://doi.org/10.1016/j.scitotenv.2017.08.251

Ekane, N., Mertz, C. K., Slovic, P., Kjellén, M., \& Westlund, H. (2016). Risk and benefit judgment of excreta as fertilizer in agriculture: An exploratory investigation in Rwanda and Uganda. Human and Ecological Risk Assessment, 22(3), 639-666. https://doi.org/10.1080/10807039.2015.1100515

Ekane, N., Nykvist, B., Kjellén, M., Noel, S., \& Weitz, N. (2014). Multi-level sanitation governance: understanding and overcoming challenges in the sanitation sector in subSaharan Africa. Stockholm Environment Institute, 4, 1-18. https://doi.org/10.3362/20461887.2014.024

Guzha, E., Nhapi, I., \& Rockstrom, J. (2005). An assessment of the effect of human faeces and urine on maize production and water productivity, 30, 840-845. https://doi.org/10.1016/j.pce.2005.08.028

Haq, G., \& Cambridge, H. (2012a). Exploiting the co-benefits of ecological sanitation. Current Opinion in Environmental Sustainability, 4(4), 431-435. https://doi.org/10.1016/j.cosust.2012.09.002

Haq, G., \& Cambridge, H. (2012b). Exploiting the co-benefits of ecological sanitation. Current Opinion in Environmental Sustainability, 4(4), 431-435. https://doi.org/10.1016/j.cosust.2012.09.002

Hulland, K., Martin, N., Dreibelbis, R., J, D. V., \& Winch, P. (2016). What factors affect sustained adoption of safe water, hygiene and sanitation technologies? A systematic review of literature. https://doi.org/10.13140/RG.2.1.5031.4329

Jewitt, S. (2011). Poo gurus? Researching the threats and opportunities presented by human waste. Applied Geography, 31(2), 761-769. https://doi.org/10.1016/j.apgeog.2010.08.003

Lamichhane, K. M., \& Babcock, R. W. (2013). Survey of attitudes and perceptions of urinediverting toilets and human waste recycling in Hawaii. Science of the Total Environment, 443, 749-756. https://doi.org/10.1016/j.scitotenv.2012.11.039

Mayo, A. W., \& Mubarak, T. (2015). Challenges of adoption of urine-diversion dry toilets technology as sanitation option by coastal communities of Mkuranga District in Tanzania, 9(May), 482-492. https://doi.org/10.5897/AJEST2014.1779

MININFRA. (2012). Sanitation and Hygiene: Policy, Stated Beliefs and Actual Practice. A Case Study in the Burera District, Rwanda, 1-17. Retrieved from www.sei-international.org 
Muellegger, E. (2005). Ecological Sanitation - a way to solve global sanitation problems ?, 31, 433-444. https://doi.org/10.1016/j.envint.2004.08.006

Mukasine, B. (2014). Ecological sanitation in Rwanda: A baseline study to identify challenges and opportunities. Conference Proceedings, 1-10.

Nhan, D. K., Verdegem, M. C. J., Binh, N. T., Duong, L. T., Milstein, A., \& Verreth, J. A. J. (2008). Economic and nutrient discharge tradeoffs of excreta-fed aquaculture in the Mekong Delta, Vietnam, 124, 259-269. https://doi.org/10.1016/j.agee.2007.10.005

Pearson, J., \& Mcphedran, K. (2008). A literature review of the non-health impacts of sanitation, 27(1). https://doi.org/10.3362/1756-3488.2008.005

Richard, C. (2015). Sanitation technology preferences \& drivers of demand for Ecological sanitation. PHD THESIS, Department of Disease Control Faculty of Infectious and Tropical Diseases Thesis Submitted for the Degree of Doctor of Philosophy, University of London July, 2015.

Robinson, B. E. (2005). Household adoption of Ecological sanitation: An Assessment of Agricultural Value and User Perspectives in Nyanza Province, Kenya.

Seleman, A., \& Bhat, M. G. (2016). Technology in Society Multi-criteria assessment of sanitation technologies in rural Tanzania : Implications for program implementation, health and socio-economic improvements. Technology in Society, 46, 70-79. https://doi.org/10.1016/j.techsoc.2016.04.003

Uddin, S. M. N., Muhandiki, V. S., Sakai, A., Al Mamun, A., \& Hridi, S. M. (2014). Sociocultural acceptance of appropriate technology: Identifying and prioritizing barriers for widespread use of the urine diversion toilets in rural Muslim communities of Bangladesh. Technology in Society, 38, 32-39. https://doi.org/10.1016/j.techsoc.2014.02.002

USAID. (2015). Assessment and improvement of sanitation and hand washing supply chain in Burera, Musanze , Nyabihu and Rubavu Districts in Rwanda : main assessment report February 2015, (February), 1-89.

Waithaka, M. M., Thornton, P. K., Shepherd, K. D., \& Ndiwa, N. N. (2007). Factors affecting the use of fertilizers and manure by smallholders: The case of Vihiga, western Kenya. Nutrient Cycling in Agroecosystems, 78(3), 211-224. https://doi.org/10.1007/s10705-0069087-x 